\title{
Gestão na educação superior e as avaliações de suas práticas
}

\author{
Management in higher education and the assessments of their practices
}

\author{
Maria Eliza Rosa Gama ${ }^{1}$ \\ ${ }^{1}$ Universidade Federal de Santa Maria | Programa de Pós-Graduação em Políticas Públicas e \\ Gestão Educacional | Santa Maria | RS | Brasil. Contato: melizagama@ yahoo.com.br. \\ ORCID: https://orcid.org/0000-0002-8789-5868
}

\author{
João Timóteo de los Santos ${ }^{2}$ \\ ${ }^{2}$ Universidade Federal do Pampa | Santana do Livramento | RS | Brasil. Contato: \\ joaotimoteodelossantos@gmail.com. ORCID: é https://orcid.org/0000-0002-6857-7813
}

\begin{abstract}
Resumo: Este artigo é fruto de uma pesquisa que teve como temática o estudo aprofundado com relação às práticas de avaliação das atividades de gestão na educação superior. Tendo como base de consulta a pesquisa bibliográfica, foram analisados estudos relacionados aos conceitos de gestão que se encaixam com as atividades educacionais do ensino superior no Brasil, bem como as diferentes possibilidades de avaliar essas atividades. O artigo expõe as características específicas de cada tipo de processo avaliativo que pode ser utilizado para avaliar a gestão educacional, com foco na avaliação participativa, que é a forma de avaliação interna apontada por autores como Denise Leite e Wagner Andriola como parte fundamental de um processo de gestão educacional participativa. O tema final abordado neste artigo faz referência aos obstáculos existentes nas instituições de ensino superior brasileiras que dificultam as práticas de autoavaliação, especificamente nos cursos de graduação.
\end{abstract}

Palavras-chave: Gestão educacional. Processo autoavaliativo. Avaliação participativa.

\begin{abstract}
This article is the result of a research that had as its theme the detailed study regarding the evaluation practices of management activities in higher education. Based on the bibliographic research, studies related to the management concepts that adapt the educational activities of higher education in Brazil were analyzed, as well as the different possibilities of evaluating these activities. The article presents the specific characteristics of each type of evaluation process that can be used to evaluate educational management, focusing on participatory evaluation, which is the method of internal evaluation pointed out by authors such as Denise Leite and Wagner Andriola as a fundamental part of a participatory educational management process. The final theme approached in this article refers to the obstacles in Brazilian higher education institutions that hinder self-assessment practices, specifically in undergraduate courses.
\end{abstract}

Keywords: Educational management. Self-assessment process. Participatory evaluation.

- Recebido em: 7 de agosto de 2018 • Aprovado em: 1 de junho de 2020

DOI: http://dx.doi.org/10.1590/S1414-40772020000200012

Este é um artigo publicado em acesso aberto sob uma licença Creative Commons https://creativecommons.org/licenses/by-nc/4.0/ 


\section{Introdução}

Este trabalho de pesquisa teve como alvo de investigação as distintas possibilidades de exercer a gestão nas instituições de ensino superior, buscando entender os formatos de gestão educacional e as possibilidades de execução de uma autoavaliação que esteja alinhada a uma proposta de gestão democrática.

O estudo identificou as dificuldades para a organização e o desenvolvimento de um processo de autoavaliação para cursos de graduação. São apresentados os conceitos de gestão educacional e avaliação institucional, com suas subdivisões.

A primeira parte do artigo aborda o tema gestão na educação superior, com foco na avaliação de suas práticas. Iniciando pela definição de gestão, que é apresentada por Castro e Werle (2004) e classificada por Wittmann e Gracindo (2001). O texto também descreve as diferentes formas de classificação para a gestão educacional, que Franco (2006) apresenta como sendo gestão propositiva, tradicional e democrática.

$\mathrm{Na}$ sequência o texto trata da avaliação institucional. Com contribuições de Leite (2006), Zainko (2008), Dias Sobrinho (2003a) e Both (2011) que auxiliam no entendimento do termo e na relação do Sistema Nacional de Avaliação (SINAES) com a construção de processos autoavaliativo nas IES.

O próximo ponto abordado fala da avaliação institucional interna, que é descrita por Leite (2006). Nesse subtítulo foi incluída a avaliação institucional participativa no ensino superior, que vem conceituada por Andriola (2005), Leite (2006), Sousa e Marcondes (2005), que salientam a importância da participação de toda a comunidade acadêmica nos processos avaliativos da IES. O termo autoavaliação institucional também foi tratado nesse subtítulo, distinguindo o mesmo de avaliação interna, evidenciando suas características pelo que dizem Zainko (2008) e Franco (2006).

$\mathrm{Na}$ sequência são tratados os desafios para a implementação da autoavaliação de cursos no Brasil. Para ilustrar quais são esses desafios foi buscado aporte no que dizem Pimenta e Anastasiou (2002). Sendo a importância de implementação desse processo autoavaliativo evidenciado Piccoli, Souza e Dalbon (2007), bem como pelas recomendações do Banco Mundial (1995) para melhorar a qualidade no ensino superior. O texto também trás contribuições de Tumolo (2010) que apresenta possibilidades para o diagnóstico autoavaliativo dos cursos de graduação. 
Finalizando o artigo, é descrita a relação entre avaliação externa e autoavaliação de cursos. Para a construção desse texto foram referenciadas as legislações em vigor no País que tratam do Sistema Nacional de Avaliação da Educação Superior (SINAES).

\section{Gestão na educação superior e as avaliações de suas práticas}

O exercício da autonomia de uma Instituição de Ensino Superior (IES), que é assegurado pela Lei de diretrizes e Bases da Educação (LDB), exige da IES o desafio de se administrar, tanto no lado financeiro como acadêmico. Esse exercício administrativo é o que Castro e Werle (2004) chamam de "Administração da Educação". Para esses autores, as políticas administrativas adotadas por uma IES, de forma a conduzir seu crescimento acadêmico, devem estar alicerçadas em três pilares que são: planejamento, gestão e avaliação da educação.

Nessa perspectiva, nota-se que a gestão ocupa o papel de executora dentro da tríade planejamento, execução e avaliação. No entanto, a gestão da educação precisa preocupar-se com os três pilares administrativos. Quando se planeja alguma ação, quando se executa essa ação e quando se avalia a efetividade dessa ação é que a gestão educacional demonstra fluir em uma IES.

Quando uma Instituição de Ensino Superior não planeja suas práticas, ou avalia seu funcionamento, não está exercendo sua autonomia, sua gestão. Pois quando ela não se apropria dessas ações, as mesmas serão desempenhadas por agentes externos.

Wittmann e Gracindo (2001) classificam a gestão educacional como uma categoria que transita entre o teórico e o prático. Sendo uma dimensão de organização e funcionamento de uma instituição, ou a ação de acompanhamento e controle da execução de um projeto ou plano. A gestão na educação constitui-se do ato de coordenar instituições e seus processos de formação.

Castro e Werle (2004) apontam que o caráter emancipatório que as IES vêm assumindo ao longo dos anos afasta a visão de administração universitária caracterizada pelo viés capitalista, em que essa instituição seguia fielmente o que o mercado exigia. Atualmente, a universidade busca cada vez mais sua emancipação do mercado, deixando de ser parte de uma empresa capitalista.

Para assumir esse novo perfil, as IES precisaram rever seus processos de gestão. Assumindo características administrativas próprias, aliadas a ferramentas de controle para suas práticas. Por isso é que a gestão universitária está ligada com planejamento e avaliação. 
Com seus Conselhos Universitários, que possuem caráter deliberativo, a universidade fortalece sua autonomia em processos decisórios. Nele a gestão superior, representada pela reitoria e direções de campi ou departamentos, respalda suas decisões com a participação democrática de todos os segmentos da comunidade acadêmica.

A gestão da educação superior pode ser exercida de diferentes formas, que são classificadas por Franco (2006) de acordo como as características que apresentam:

Gestão Propositiva: essa forma de gestão considera as inovações que estão ocorrendo no panorama internacional para guiar as práticas de gestão na IES, mantendo vínculo com as demandas do mercado para pensar seu projeto institucional. Destaca-se o incremento da participação discente, bem como de equipe técnica administrativa capacitada e de docentes nos processos decisórios. No entanto, esse modelo de gestão abre mão da autonomia institucional, cedendo ao controle do estado, que assume papel de supervisor.

Gestão Tradicional: modelo de gestão espelhado nas relações entre educação e sociedade. Seu modo administrativo pode oscilar em quatro formas distintas: por meio de colegiados, que enfatiza a cooperação da comunidade acadêmica nas decisões da instituição; pelo caráter burocrático, que enfatiza o grau hierárquico das autoridades para a tomada de decisões; pelo aspecto profissional, que espelha suas decisões sob o ponto de vista das autoridades especialistas no tema em discussão e pelo caráter político, caracterizado pela presente competição entre grupos de gestores que seguem ideais distintos.

Gestão democrática: compreende o exercício de administrar instituições, suas políticas, projetos e programas, incorporando processos que permitam não só a participação dos gestores nas tomadas de decisões, mas também dos responsáveis e beneficiários dos resultados. É marcante nessa forma de gestão a presença de instrumentos como assembleias, audiências públicas, plenárias, reuniões, fóruns, congressos, conferências, entre outros, que asseguram a democracia representativa e participativa.

A gestão universitária diz respeito ao pensar a universidade no sentido de entender qual sua finalidade. É saber o que a instituição precisa buscar para atingir seus objetivos propostos em seu planejamento institucional estratégico. Esse planejamento é espelhado no Plano de Desenvolvimento Institucional (PDI), que é a ferramenta construída com a participação democrática da comunidade acadêmica para nortear os caminhos da IES.

\footnotetext{
Pode-se, pois, considerar que a Gestão Universitária é um fenômeno cultural, produzido pela linguagem, pelos discursos; um fenômeno político, de construção de projetos/ideias, de fazer opções, de decidir quanto a regras de convivência e de credenciamento; portanto, um fenômeno de relações/ações humanas (FRANCO, 2006, p. 216).
} 
A gestão das universidades públicas brasileiras atualmente é pautada pelos princípios democráticos. Conforme previsto na LDB: "As instituições públicas de educação superior obedecerão ao princípio da gestão democrática, assegurada a existência de órgãos colegiados deliberativos, de que participarão os segmentos da comunidade institucional, local e regional” (BRASIL, 1996, p. 25, Art. 56).

Por isso, as IES públicas brasileiras geralmente têm seus cargos diretivos definidos a cada quatro anos mediante processo de consulta à comunidade acadêmica. Bem como, suas regulações lavradas em forma de portarias ou resoluções, as quais mesmo sendo pensadas pela gestão, só são validadas após aprovação dos conselhos universitários.

\section{Avaliação institucional}

O termo avaliação institucional, de uma forma geral, tem em seu significado a avaliação de práticas de uma instituição. Podendo ser na área de saúde, educação, segurança, entre outras. "O termo é empregado para a avaliação de políticas públicas, em especial das políticas setoriais e instituições prestadoras de serviços públicos.” (LEITE, 2006, p. 465) considerando a avaliação de planos e projetos praticados por essas instituições.

Um processo de avaliação institucional permite realizar o balanço das ações desenvolvidas, de forma que os rumos da instituição sigam no sentido da qualidade. Por isso, esse processo constitui-se como um serviço prestado à sociedade, que é a usuária do que é oferecido pelas instituições públicas.

A avaliação institucional pode ser exercida de duas formas: como avaliação externa, feita por órgão regulador, ou avaliação interna, feita por pessoal da própria instituição.

A avaliação institucional na educação superior brasileira também segue a sistemática de subdivisão em avaliações externas e internas. Para Leite (2006), a avaliação do sistema educacional brasileiro é assumida como uma estratégia capaz de propiciar o alcance dos objetivos de melhoria da eficiência e da qualidade da educação,

Com relação à avaliação de uma IES, Zainko (2008) defende que ela deva possibilitar a construção de um projeto de desenvolvimento acadêmico sustentado por princípios como a democracia, a autonomia, a pertinência e a responsabilidade social.

Foi com a implantação da lei do Sistema Nacional de Avaliação da Educação Superior (SINAES), conforme lei $\mathrm{n}^{\circ} 10.861$, de 14 de abril de 2004, que a avaliação institucional ganhou espaço nas atribuições do estado. Essa nova proposta de avaliação caracteriza-se por 
considerar a avaliação das IES como o objeto central desse sistema, primando pelo respeito as características individuais de cada instituição.

Esse novo processo de avaliação institucional estabeleceu como modalidades a Avaliação das Instituições de Educação Superior (AVALIES), a Avaliação do Desempenho dos Estudantes (ENADE) e a Avaliação dos Cursos de Graduação (ACG), contemplando na avaliação institucional dois momentos principais, que são: autoavaliação, realizada pelas CPAs e avaliação externa, que é realizada por uma comissão designada pelo Inep, seguindo diretrizes estabelecidas pela Comissão nacional de Avaliação da Educação superior.

O objetivo a ser alcançado pelo SINAES é de "traçar um panorama da qualidade dos cursos e das instituições de ensino, fornecendo à sociedade informações sobre a educação superior no País.” (ZAINKO, 2008, p. 96). Esse sistema avaliativo da educação superior já é considerado alicerçado como uma política de governo para avaliação das IES, e na opinião de Dias Sobrinho (2003a) poderá servir como um dos pilares para se debater as propostas de reforma universitária que vem sendo discutidas no País. O autor afirma que esse mecanismo de avaliação institucional possui forte significado político e importante dimensão não só técnica, como ética. Pois sempre se produz em um espaço social de valores e disputas de poder.

É preciso conhecer a força transformadora da avaliação nas mudanças desejadas para a educação superior do País. Dias Sobrinho (2003b) relata que em muitos países desenvolvidos a avaliação da educação superior é tida como referencial para pensar novas políticas educacionais. Essa avaliação é considerada como instrumento da reforma do estado. Para o autor, nenhum estado moderno desenvolvido pode abrir mão da avaliação, que tem papel central nas reformas da educação superior.

Reforçando a importância que deve ser dada a avaliação, Both (2011) ressalta que toda a ação de avaliar deve vir acompanhada de tomadas de decisões a partir dos resultados demonstrados. "Com os resultados de avaliação à disposição, nada é mais importante que providenciar medidas acadêmicas realmente corretivas, sob pena de se cair em fracasso acadêmico, tanto na forma científica, técnica e administrativa" (BOTH, 2011, p. 168).

Zainko (2008) defende que a avaliação institucional foi proposta pelo SINAES como sendo uma ferramenta organizadora da coerência do processo avaliativo que se desenvolve nas IES

Envolvendo objeto, sujeitos e processos, a avaliação proposta tem como objeto a análise das dimensões, das estruturas, das relações, das atividades, das funções e das finalidades de uma IES; como sujeitos os conjuntos de professores, estudantes, funcionários e membros da comunidade externa especialmente convidados ou 
designados; como processos avaliativos o autodiagnóstico e a avaliação externa resultantes de procedimentos institucionais que se utilizam da infraestrutura da própria instituição (ZAINKO, 2008, p. 99).

Com relação à avaliação institucional externa, pode se dizer que é o procedimento operado de fora para dentro de uma instituição. Seus operadores são órgãos do governo ou agências reguladoras, governamentais ou não governamentais. Quando feita por agências reguladoras, essa avaliação tem como objetivo identificar se a instituição avaliada ajusta-se as exigências do mercado. "Sua função é fornecer dados objetivos e confiáveis para a efetividade de políticas governamentais de regulação do sistema e fornecer informações para as escolhas dos usuários" (LEITE, 2006, p. 467).

A avaliação externa, exercida por órgãos governamentais, tem como principal característica a execução do controle e supervisão dessas instituições.

\section{Autoavaliação ou Avaliação institucional interna}

Conforme descrito na lei do SINAES, a avaliação da educação superior é sempre institucional, desenvolvendo-se como processo e tendo com base tanto as autoavaliações como as avaliações externas.

Com relação a essa autoavaliação descrita pelo SINAES como integrante da avaliação institucional, Leite (2006) faz uma análise entre avaliação interna e autoavaliação. Distinguindo ambas pelas seguintes caraterísticas de cada uma: a autoavaliação institucional é o processo interno de avaliação realizado pelos integrantes da instituição que se envolvem como avaliadores e/ou avaliados. Isto é, “eles são não só sujeitos mas também parte do objeto de avaliação" (LEITE, 2006, p. 466).

A autora denomina autoavaliação como sendo um processo de autoanálise, que destaca os pontos fortes e os desafios que a instituição precisa enfrentar para melhorar a qualidade do seu fazer acadêmico, superando dificuldades e fragilidades apontadas.

Uma avaliação interna é aquela em que, segundo Leite (2006), a instituição orienta-se por indicadores externos e é operada por comissões próprias para esse fim. A existência dessa comissão caracteriza esse processo avaliativo como sendo uma análise interna feita de forma independente. Que mesmo sendo composta por pessoas vinculadas à instituição, tem caráter avaliador das práticas da instituição que não envolve a equipe avaliadora. Coloca-se essa comissão em um patamar superior, que avalia de cima para baixo.

Mesmo tendo essas características marcantes, a autora destaca que a avaliação interna pode ser participativa: 
Existe forte possibilidade de o processo ser participativo, dirigido ao social e destinado aos próprios sujeitos para efeitos de melhoria institucional, individual e coletiva. Isto estaria mais de acordo com os costumes acadêmicos, fundados nos princípios da autonomia e zelosos das práticas da colegialidade e das práticas democráticas institucionais (LEITE, 2006, p. 466).

Em um primeiro conceito para o termo avaliação participativa, define-se como sendo o processo avaliativo que conta com a participação de todos os segmentos da comunidade avaliada. Com relação as instituições educacionais de ensino superior, essa comunidade é composta por seus quadros de servidores docentes, técnicos administrativos e de seu corpo discente.

$\mathrm{Na}$ gestão das instituições públicas de ensino superior brasileiras a presença desses segmentos da comunidade é assegurada por meio de representações dessas categorias em seus conselhos superiores. Sendo também exigida a presença de representação da comunidade externa para alguns desses conselhos.

Para avaliar o que é planejado e executado coletivamente em uma Instituição de Ensino Superior também é necessária a presença desses segmentos da comunidade acadêmica. A lei do SINAES, quando trata da composição das Comissões Próprias de Avaliação (CPAs), aponta claramente essa necessidade como exigência legal:

\footnotetext{
Art. 11. Cada instituição de ensino superior, pública ou privada, constituirá Comissão Própria de Avaliação - CPA, no prazo de 60 (sessenta) dias, a contar da publicação desta Lei, com as atribuições de condução dos processos de avaliação internos da instituição, de sistematização e de prestação das informações solicitadas pelo INEP, obedecidas as seguintes diretrizes:

I - constituição por ato do dirigente máximo da instituição de ensino superior, ou por previsão no seu próprio estatuto ou regimento, assegurada a participação de todos os segmentos da comunidade universitária e da sociedade civil organizada, e vedada a composição que privilegie a maioria absoluta de um dos segmentos (BRASIL, 2004, Seção 1, n. 72, p. 4).
}

Pode-se dizer que a implantação de um processo participativo de avaliação ou autoavaliação institucional passa pela implantação das CPAs. Por isso, deve-se ter o cuidado na definição das representações e escolha democrática dos membros para essas Comissões. Andriola (2005) alerta que se não existir o envolvimento da comunidade, já a partir da escolha dos membros da CPA, a avaliação deixará de caracterizar-se como atividade democrática e participativa.

As CPAs passaram a ser regulamentadas em agosto de 2004, pelo documento da Comissão Nacional de Avaliação da Educação Superior (CONAES), intitulado Diretrizes para avaliação das instituições de ensino superior, que especificou as atribuições dessas comissões. 
As CPAs são responsáveis pela condução dos processos internos de avaliação nas IES. Elas são consideradas órgãos de representação acadêmica e não administrativa da instituição.

O formato de avaliação institucional participativa pode seguir duas vertentes, que são apresentadas por Leite (2006) como sendo: Primeira vertente, que é aquela conduzida por avaliadores profissionais em conjunto com os gestores da instituição. Essa vertente é caracterizada pela pesquisa-ação, e o avaliador tem a atribuição de treinar o pessoal participante para que possam dar continuidade a outros processos de avaliação. "Neste formato avaliativo os usuários aprendem a fazer avaliação junto com os profissionais avaliadores" (LEITE, 2006, p. 500).

A segunda vertente aproxima-se mais dos processos de autoavaliação ou avaliação interna. A avaliação é centrada na participação de sujeitos que vivem o dia a dia da instituição. "Não há avaliadores especializados, os sujeitos participantes são atores e autores da avaliação.” (LEITE, 2006, p. 500). A autora classifica a avaliação que segue essa segunda vertente como sendo um instrumento de responsabilidade democrática e política, que segue metodologias qualitativas e quantitativas para informar processos e decisões, proporcionando autoanálise, autocrítica e autovigilância.

Para Andriola (2005), o processo de autoavaliação de uma instituição de ensino superior é um exemplo de atividade que deva ter caráter marcantemente participativo e democrático. $\mathrm{O}$ autor destaca a necessidade de se buscar ampla mobilização dos setores que compõem essas instituições educacionais. Esses setores são representados por docentes, discentes e servidores técnicos administrativos que integram essas IES.

Para marcar a diferença entre um processo avaliativo transparente, democrático e participativo de outro obscuro, centralizador e antidemocrático, o autor afirma ser imprescindível contar com a participação dos três grupos de atores institucionais: corpo docente, discente e técnico administrativo.

Para que um processo de autoavaliação seja caracterizado como atividade participativa e democrática é preciso que os agentes engajem-se na participação ativa, de forma a surtir os efeitos desejados advindos dessa mobilização.

Entre os objetivos da autoavaliação participativa, Andriola (2005) destaca o aumento da consciência política e cidadã dos atores institucionais, e essa avaliação é vista como sendo uma tarefa eminentemente formativa. Outro objetivo desse tipo de autoavaliação, apontado pelo autor, é que a mesma servirá para o aprimoramento da realidade educacional avaliada. 
Outros aspectos da realidade institucional também podem ser aprimorados com base nos resultados obtidos pela autoavaliação: o primeiro refere-se a mudança da comunidade interna a respeito da importância da avaliação. Também poderá ocorrer o engajamento dessa comunidade nas discussões e na busca de soluções inovadores para alguns problemas detectados. Mas o que mais se destaca na comunidade acadêmica é a mudança geral na práxis desses atores, mudando a forma como veem-se dentro da IES. Passando a se enxergarem como agentes atuantes na vida institucional.

Sousa e Marcondes (2005) acrescentam que o caráter participativo deve estar presente não só na avaliação, mas também na autoavaliação. Por esse motivo, os documentos orientadores desses processos avaliativos emitidos pelo Ministério da Educação (MEC) destacam a importância da sensibilização da comunidade acadêmica, para que a mesma seja partícipe desses processos avaliativos.

Em uma Avaliação Participativa (AP) não pode haver espaço para um agente centralizador. Aquele participante que, detentor do conhecimento a respeito da avaliação, domina as discussões e tem seu ponto de vista como o norte para os demais participantes. Todos os participantes devem ter voz em todo o processo avaliativo. Leite e Nunes (2009) destacam que esse expert em avaliação não pode receber destaque nas comissões avaliativas. Pois converterá num dominante do processo avaliativo, que não dá voz aos demais participantes. Os protagonistas de uma Avaliação Participativa tem a tarefa de produzirem conhecimento sobre si, sobre a instituição e sobre suas relações. A AP é "uma forma de conhecimento social por todos produzida e em permanente reconstrução" (LEITE; NUNES, 2009, p. 152).

Uma autoavaliação é um processo de autoconhecimento que passa um curso ou instituição, avaliando o que é, e analisando o que pretende ser.

\footnotetext{
Por meio de processos de autoanálise, questões como o que foi realizado, como se dá a administração, quais as informações disponíveis para análise e interpretação, quais os pontos fortes e as fragilidades da instituição no seu todo, servem de base para a elaboração de relatório com a identificação de práticas exitosas, para serem divulgadas, e de equívocos, para poderem ser evitados no futuro (ZAINKO, 2008, p. 99).
}

Com a criação do programa de Avaliação das Instituições de Educação Superior (AVALIES), implantado pela lei do SINAES, passou-se a exigir das IES a coleta de informações válidas e confiáveis em seus processos autoavaliativos, bem como o uso efetivo de seus resultados. Pois estes também subsidiarão as avaliações externas. 
Assim, adquire importância nesse processo a Avaliação Interna, ou seja, a Autoavaliação:

Que se configura num processo contínuo de construção de conhecimentos sobre a própria realidade institucional, a fim de compreender os significados do conjunto das atividades desenvolvidas para melhorar a qualidade educativa e alcançar maior relevância social, identificar pontos fracos e fortes, potencialidades, e estabelecer estratégias de superação de problemas (FRANCO, 2006, p. 193).

Os requisitos básicos são: a formação da Comissão Própria de Avaliação - CPA; a participação de todos os segmentos da instituição nesta Comissão; o compromisso explícito por parte dos dirigentes das IES em manter um programa de autoavaliação.

Em suas diretrizes, o SINAES define a autoavaliação como sendo um processo cíclico, criativo e renovador de análise, interpretação e síntese das dimensões que definem a instituição. É por meio dela que torna possível fazer uma reflexão da instituição como um todo. Avaliando seu passado e presente para pensar o seu futuro.

O Instrumento de Avaliação de Cursos de Graduação, em vigor desde outubro de 2017, descreve a autoavaliação institucional de seguinte forma:

\footnotetext{
A autoavaliação institucional tem como objetivos produzir conhecimentos, refletir sobre as atividades cumpridas pela instituição, identificar as causas dos seus problemas, aperfeiçoar a consciência pedagógica e capacidade profissional do corpo docente e técnico-administrativo, fortalecer as relações de cooperação entre os diversos atores institucionais, tornar mais efetiva a vinculação da instituição com a comunidade, além de prestar contas à sociedade (INEP, 2017, p. 45).
}

Sousa e Marcondes (2005) mostram preocupação como três aspectos importantes em um processo de autoavaliação: Para que avaliar? O que avaliar? Como avaliar?

Assegurar a participação da comunidade acadêmica nos processos de autoavaliação parece ser um desafio que deve ser enfrentado pelas IES. Principalmente por aquelas de médio e grande porte, estruturadas em multicampia, com diversidade de cursos, grande número de alunos, docentes e servidores técnicos administrativos.

Uma característica marcante na participação de toda a comunidade acadêmica nesses processos avaliativos, principalmente nos processos de autoavaliação, é a heterogeneidade de pensamentos. $\mathrm{O}$ ambiente acadêmico é composto por diferentes linhas filosóficas, causando distintas interpretações e conclusões. "As óticas específicas, esses juízos particulares de sujeitos e grupos, tendem a definir diferentes indicadores." (SOUSA; MARCONDES, 2005, p. 26). Isso poderá acarretar diferentes expectativas para as questões que compõem um processo de avaliação. 
Para atenuar esse problema, os autores sugerem que um processo de autoavaliação conte com a presença de um avaliador externo, que denominam de "avaliador parceiro". Esse avaliador será convidado pelo grupo e se propõe a colaborar na execução de trabalhos de iniciativa da equipe, procurando manter relação de confiabilidade com o grupo e atuando como mediador.

Uma avaliação participativa pressupõe um exercício de autonomia para a instituição de ensino. Uma forma de fortalecer o diálogo entre a gestão e demais integrantes da comunidade acadêmica, "o pensar junto, a construção sócio individual, que implica no compromisso com a ação" (SOUSA; MARCONDES, 2005, p. 28).

\section{Desafios para implementar a autoavaliação nos cursos de graduação do país}

Em um curso de graduação, a avaliação tem como foco o seu projeto político e pedagógico, analisando a implementação deste e seu reflexo no funcionamento do curso. $\mathrm{O}$ resultado de uma avaliação "permite a correção de rumos e processos, a partir da identificação de sucessos e falhas, de forma que os resultados desejados sejam alcançados com maior eficiência e aptidão" (PICCOLI; SOUZA; DALBON, 2007, p. 23).

A não obrigatoriedade de existência dos instrumentos de autoavaliação nos cursos de graduação pela lei do SINAES pode ser notada claramente quando, em seu texto, a referida lei traz a tona a necessidade de criação das CPA, que terão como atribuição desenvolverem instrumentos de autoavaliação institucionais. Nota-se, por tanto, que a autoavaliação institucional ganha destaque entre as ferramentas avaliativas em vigor, mas tem como seu foco a IES em seu todo.

É possível que, ao avaliar internamente uma Instituição, sua Comissão também atente para aspectos específicos dos cursos existentes na referida IES. Mas essa não é uma regra a ser seguida, pois o SINAES não expressa a avaliação dos cursos de graduação como sendo atribuição das CPAs.

Para o Banco Mundial (1995, p. 78), no documento intitulado La Enseñanza Superior: las lecciones derivadas de la experiencia, o principal fator determinante para o desenvolvimento acadêmico está condicionado a criar nas IES a capacidade de avaliar e vigiar a qualidade de seus processos de ensino. Esse mesmo documento faz alusão a importância de existirem os mecanismos institucionais de autoavaliação. Que são considerados fundamentais para promoverem um sentido de verdadeira responsabilidade institucional. "Em vários países, as universidades examinam periodicamente o trabalho realizado com objetivo de julgar, entre 
outras coisas, a qualidade e a pertinência dos programas, a eficiência interna e a necessidade de financiamentos” (BANCO MUNDIAL, 1995, p 78-79. Traduzido pelo autor).

Parece que os legisladores já notaram a lacuna deixada com relação à criação de instrumentos específicos para autoavaliação dos cursos de graduação. Pois no volume 5 do periódico que trata do SINAES, os pesquisadores do INEP expõem que "[...] a avaliação interna ganha destaque na avaliação institucional por ter como foco a IES como um todo, mas é imprescindível que ela contemple os cursos." (INEP, 2015, p. 34).

Os cursos também precisam ter seus instrumentos de autoavaliação. Podendo estes serem desenvolvidos a partir das discussões feitas nos Núcleos Docentes Estruturantes (NDEs) e nas comissões dos cursos. O SINAES não inclui como atribuição das CPAs a aplicação de autoavaliação nos cursos, mas essa falha legislativa não impede a referida comissão de contribuir com os processos de autoavaliação dos cursos de graduação. Talvez seja essa lacuna na lei do SINAES que contribui para a não execução dos referidos processos.

Já no ano de 2002, antes mesmo da implantação do SINAES e de se cogitar a institucionalização da autoavaliação nas IES, alguns pesquisadores já defendiam que, baseados na pesquisa pedagógica, os professores do ensino superior precisavam dedicar parte de seus trabalhos para investigar suas próprias práticas, seria o início do que hoje descreve-se como autoavaliação. Segundo apontado por Pimenta e Anastasiou (2002, p. 190), as exigências da legislação brasileira com relação à qualificação dos professores para o ensino superior, faz com que sua grande maioria seja de profissionais com conhecimento de pesquisa, facilitando o desenvolvimento de algum tipo de trabalho que analise suas práticas acadêmicas.

No entanto, para as autoras, desenvolver um trabalho de pesquisa que tenha como foco as práticas docentes não é uma tarefa fácil. Principalmente quando os resultados encontrados não condizem com os esperados. Cabendo ao pesquisador a tarefa de direcionar seus colegas no sentido de reverem suas ações docentes.

Tomar decisões sobre as ações docentes em equipe é posicionar-se, deixar-se conhecer profissionalmente, substituir formas inicialmente pensadas por outras, definidas pelo coletivo. Exige flexibilidade para atuar e alterar formas de ação. Exige saber ouvir, ponderar, decidir (PIMENTA; ANASTASIOU, 2002, p. 193).

Para Tavares et al. (2014, p. 95), desde a década de 1990 na América Latina, já se pensava em desenvolver sistemas avaliativos para o ensino superior que tivessem como objetivo identificar nas IES as fragilidades que deveriam ser enfrentadas e as potencialidades 
a serem fortalecidas. Nesse contexto, a autora destaca a importância da autoavaliação para desenvolver a formação e o autoconhecimento das instituições. Fortalecendo a perspectiva da emancipação dessas IES com relação ao controle do estado.

A escassez de bibliografias que descrevam como deve ser um instrumento para autoavaliação de cursos de graduação, e a lacuna deixada pela legislação vigente com relação a esta etapa avaliativa, levam alguns pesquisadores a defenderem a utilização de instrumentos de avaliação externa como ferramentas possíveis de serem utilizadas para autoavaliação desses cursos.

Tumolo (2010, p. 3) afirma que dois dos instrumentos de avaliação constantes no ENADE podem servir ao diagnóstico autoavaliativo dos cursos de Graduação. A autora discorre sobre o questionário do estudante e o questionário do Coordenador do curso, caracterizando ambos como sendo partes que subsidiam a autoavaliação do curso.

\footnotetext{
O questionário do estudante é o instrumento que objetiva traçar o perfil dos estudantes, ingressantes e concluintes, dos cursos de graduação do País; conhecer a opinião dos estudantes sobre o ambiente acadêmico em que realizam a sua formação e consolidar informações para promover a melhoria das condições de ensino e dos procedimentos didático-pedagógicos. O questionário do Coordenador tem o objetivo de reunir informações que contribuam para a definição do perfil do curso. Ele possibilita investigar a percepção do coordenador sobre aspectos pedagógicos e estruturais do curso (TUMOLO, 2010, p. 3).
}

Como o ENADE é composto por esses dois indicadores e mais a prova aplicada ao aluno, e esta última representará $100 \%$ da nota do aluno, a autora não visualizou o caráter avaliativo externo dos dois primeiros instrumentos. Mesmo descrevendo que "os resultados do questionário do estudante geram diretamente $10 \%$ do Conceito Preliminar do Curso (CPC)" (TUMOLO, 2010, p. 4). Assim, ela incorpora ao ENADE a característica de ser um "processo de autoconhecimento e de autoavaliação para os cursos de graduação" (p. 1).

\section{Avaliação externa e sua inter-relação com a necessidade de autoavaliar os cursos de graduação}

O SINAES regulou a avaliação da educação superior no País por meio da avaliação de Instituições de Ensino Superior, de cursos e do desempenho dos estudantes. Tais avaliações são de responsabilidade da Diretoria de Avaliação da Educação Superior (DAES) e do Instituto Nacional de Estudos e Pesquisas Educacionais Anísio Teixeira (INEP), com a orientação da Comissão Nacional de Avaliação da Educação Superior (CONAES). Esse processo avaliativo educacional tem entre seus objetivos a melhoria da qualidade da educação 
superior e a expansão da sua oferta. Para atender a esses objetivos, a constante avaliação das instituições de ensino superior assume importante papel.

\footnotetext{
Os cursos de todas as organizações acadêmicas submetem-se aos atos regulatórios de reconhecimento e de renovação de reconhecimento, este, por sua vez, está atrelado ao Conceito Preliminar de Curso (CPC), cujo resultado satisfatório dispensa a visita. A avaliação de cursos de graduação é organizada com base em três dimensões: organização didático-pedagógica; corpo docente e tutorial; e infraestrutura (INEP, 2015, p. 34).
}

O primeiro instrumento de avaliação de cursos entrou em vigor o ano de 2010. A partir disso, o Inep vem constantemente reformulando esses instrumentos de avaliação. O referido instrumento já passou por, pelo menos, duas atualizações significativas, sendo a primeira em 2012 e as mais recentes realizadas em 2015 e 2016 e 2017. No entanto, esse último instrumento ainda não está sendo aplicado.

As avaliações de cursos feitas pelo Inep têm como meta atender dois objetivos gerais, sendo eles: autorização ou credenciamento, reconhecimento e renovação de reconhecimento. Nesse processo de avaliação dos cursos de graduação, o Inep também desenvolve a avaliação do desempenho discente. Para a autorização ou credenciamento de cursos, o foco da avaliação está no projeto do curso, apurando o que é pretendido pela IES. Já nos atos de reconhecimento, renovação de reconhecimento e recredenciamento é avaliado o projeto implementado.

São três as dimensões a serem avaliadas nos cursos de graduação: a primeira refere-se a dimensão da organização didático pedagógica, que avaliará como se desenvolve o projeto político pedagógico do curso; a segunda dimensão refere-se ao perfil docente, analisando os perfis dos profissionais que integram o corpo docente do referido curso, além do perfil dos discentes; a última dimensão é a que analisa as condições das dependências físicas do curso, analisando onde acontece o processo de ensino. Para essas três dimensões são criados indicadores que nortearão suas avaliações.

A escala de conceitos para avaliação dos cursos de graduação segue a mesma tabela de pontuação adotada pelo SINAES nas avaliações institucionais, recebendo o conceito 1 aquele indicador que não existir no curso. Essa metodologia de pontuação torna mais clara a interpretação dos conceitos mais baixos, já que ao conceituar um indicador com 2, significará dizer que o mesmo é insuficiente, diferenciando-o de quando o mesmo não existir. A partir do conceito 3 é que um indicador passa a ser considerado suficiente, podendo ser classificado 
como muito bom quando receber conceito 4 e chegar até sua excelência quando atingir o conceito 5 .

Cabe lembrar que os pesos para cada dimensão mudam de acordo como o ato regulatório. Quando o MEC está desenvolvendo o processo de autorização de um curso de graduação, a dimensão que recebe maior peso avaliativo é a que refere-se à infraestrutura, já nos processos de reconhecimento ou renovação de reconhecimento, a maior pontuação está voltada para a organização didático pedagógica. Isso é justificado pois é nessa etapa que está se desenvolvendo o projeto pedagógico do curso em avaliação. Essa avaliação do projeto pedagógico é feita com base no PDI da IES, devendo estar os dois documentos em consonância um com o outro.

A partir da etapa de autorização, a instituição precisa focar seus esforços no trabalho acadêmico. A preocupação do avaliador deixa de ser nas instalações físicas que asseguram a implantação do curso, e passa para a preocupação em atingir sua excelência acadêmica, tanto com relação ao corpo docente, como com o projeto político pedagógico do curso.

Muitas vezes são observados que projetos autorizados e credenciados com notas máximas nem sempre são concretizados pelas instituições proponentes. Isso ocorre porque provavelmente o que foi pensado não condiz com a realidade financeira ou acadêmica da instituição.

Com a possibilidade das próximas avaliações externas nos cursos de graduação, na modalidade visita in loco, ficarem condicionadas à obtenção de nota baixa no Conceito Preliminar de Curso (CPC), os cursos que obtiverem pontuação suficiente no CPC não serão contemplados com essa etapa avaliativa do SINAES. Refletindo assim, a diminuição ainda maior das avaliações externas presenciais, o que reforça a necessidade das instituições criarem seus próprios mecanismos de avaliação dos cursos para que consigam projetar seus índices de satisfação sem a necessidade de dependência das avaliações externas in loco feitas pelo INEP.

Segundo o Inep (2015, p. 23), são atribuídos para o $\mathrm{CPC}^{1}$ os conceitos que vão de 1 até 5. Dessa forma, os cursos que obtiverem CPC 3, 4 ou 5 têm a prerrogativa de dispensar a visita dos avaliadores. Nesse caso, o conceito preliminar automaticamente passa a ser o Conceito do Curso (CC).

\footnotetext{
${ }^{1}$ O CPC, criado pela Portaria Normativa MEC no 4, de 5 de agosto de 2008 e ratificado na Portaria $\mathrm{n}^{\circ}$ 40/2007, editada em 2010, consubstancia os resultados do ENADE e complementa o diagnóstico inicialmente traçado por meio do Indicador de Diferença entre os Desempenhos Observado e Esperado (IDD). Na composição desse índice, são agregados outros componentes à avaliação, tais como infraestrutura e corpo docente. Além disso, por meio do questionário do estudante, reúnem-se dados sobre infraestrutura, instalações físicas e recursos didático-pedagógicos oferecidos pelo curso. Outro insumo na composição do CPC é coletado no cadastro docente e se refere à titulação e ao regime de trabalho.
}

Avaliação, Campinas; Sorocaba, SP, v. 25, n. 02, p. 458-476, jul. 2020 
O mesmo texto diz que os cursos que obtiverem CPC 1 ou 2 devem obrigatoriamente solicitar a avaliação in loco para que recebam um novo conceito, que poderá ser igual, maior ou menor que o CPC.

\section{Considerações finais}

A temática específica do estudo voltou-se para as peculiaridades do desenvolvimento dos processos de autoavaliação de cursos de graduação. Identificou-se que muito pouco é estudado com relação à autoavaliação de cursos de graduação. Também foi identificado que, desde sua implantação, o Sistema Nacional de Avaliação da Educação Superior (SINAES) não incluiu esse processo avaliativo em suas exigências.

A necessidade de se organizar um processo de autoavaliação para os cursos de graduação ganhou importância maior a partir do instrumento de avaliação externa de 2015, em que o Ministério da Educação (MEC) inclui o relatório de Autoavaliação Institucional como fonte de consulta para o avaliador externo de cursos de graduação. Devendo este avaliador utilizar o relatório da autoavaliação institucional para extrair dele os subsídios que lhe auxiliarão.

Os processos autoavaliativos têm como característica a participação de toda a comunidade acadêmica. Pois autoavaliar é avaliar a si mesmo. Diferente de avaliar internamente, que é o processo avaliativo em que um determinado grupo tem a função de avaliar outro grupo da mesma organização.

O tema central deste artigo faz referência a gestão dos cursos de graduação, que carecem de instrumentos autoavaliativos que possam medir de forma efetiva as práticas desses cursos. Ficou evidenciado que os cursos de graduação não recebem a mesma atenção que o SINAES despende às IES com relação a sua avaliação interna. Esse exercício individual para cada curso de graduação só acontece quando a gestão institucional o dos cursos entender que é necessário.

Mesmo sendo externado como necessário por organizações internacionais e indiretamente por normativas nacionais, esse processo autoavaliativo caminha em passos lentos, ficando atrás da autoavaliação institucional, que está alicerçada pelas Comissões Próprias de Avaliação. Considerando a autoavaliação de cursos como uma forma de pesquisa educacional, podemos aferir que essa modalidade avaliativa não ganha folego por conta de atingir diretamente as práticas docentes, e estes não sentem-se confortáveis em se autoavaliarem. 


\section{Referências}

ANDRIOLA, Wagner Bandeira. Desafios e necessidades que se apresentam às Comissões Próprias de Avaliação (CPAs) das Instituições de Educação Superior (IES), visando à Implementação do Sistema Nacional de Avaliação da Educação Superior (SINAES). In: RISTOFF, Dilvo I. Avaliação participativa: perspectivas e desafios. Brasília: INEP, 2005.

BANCO MUNDIAL. La enseñanza superior: las lecciones derivadas de la experiencia (Primera Edición en español). Washington, D.C.: BIRF/BM, 1995.

BOTH, Ivo José. Avaliação: “voz da consciência” da aprendizagem. Curitiba: Ibpex, 2011.

BRASIL. Lei 9.394, de 20 de dezembro de 1996. Estabelece as diretrizes e bases da educação nacional. Diário Oficial da União, Brasília, DF, 23 dez. 1996.

BRASIL. Lei no 10.861, de 14 de abril de 2004. Institui o Sistema Nacional de Avaliação da Educação Superior - SINAES e dá outras providências. Diário Oficial da União, Brasília, DF, 15 abr. 2004.

CASTRO, Marta Luz Sisson de; WERLE, Flávia Obino Corrêa. Administração comparada com área temática: periódicos brasileiros 1982 e 2000. Revista Educação, Porto Alegre, v. 27, n. $2,2004$.

DIAS SOBRINHO, José. Avaliação: políticas educacionais e reformas da educação superior. São Paulo: Cortez, 2003a.

DIAS SOBRINHO, José. Políticas de avaliação, reformas de Estado e da educação superior. In: ZAINKO, Maria Amélia Sabbag (org.). Políticas e gestão da educação superior.

Curitiba: Champagnat; Florianópolis: Insular, 2003b. p. 61-90

FRANCO, Maria Estela Dal Pai. Gestão e modelos da educação superior. In: MOROSINI, Marilia Costa (org.). Enciclopédia de pedagogia universitária. Brasília-DF: Inep/MEC, 2006. v. 2.

INEP - Instituto Nacional de Estudos e Pesquisas Educacionais Anísio Teixeira. Sistema Nacional da Avaliação da Educação Superior. Brasília: INEP/MEC, 2015. v. 5 Avaliação in loco: referenciais no âmbito do SINAES.

INEP - Instituto Nacional de Estudos e Pesquisas Educacionais Anísio Teixeira. Instrumento de avaliação de cursos de graduação presencial e a distância: reconhecimento e renovação de reconhecimento, versão 2017. Brasília: Inep/MEC, 2017.

LEITE, Denise. Avaliação da educação superior. In: MOROSINI, Marilia Costa (org.). Enciclopédia de pedagogia universitária. Brasília-DF: Inep/MEC, 2006. v. 2.

LEITE, Denise; NUNES, Ana Karin. Avaliação participativa: constatações e aprendizagens. Revista Contexto e Educação, Ijuí, v. 24, n. 81, p. 147-169, jan./jun. 2009.

PIMENTA, Selma Garrido; ANASTASIOU, Léa das Graças Camargos. Docência no ensino superior. São Paulo: Cortez, 2002. v. 1. 
PICCOLI, Humberto Camargo; SOUZA, Roni de Azevedo; DALBON, Antônio Carlos Sampaio. Autoavaliação institucional 2005/2006. Rio Grande: FURG, 2007.

SOUSA, Clarilza Prado de; MARCONDES, Anamérica Prado. Buscando possibilidades para a avaliação institucional da educação superior. Avaliação, Campinas; Sorocaba, v. 10, n. 4, p. 23-38, dez. 2005. Disponível em:

http://periodicos.uniso.br/ojs/index.php/avaliacao/article/view/1323/1313. Acesso em: 14 out. 2017.

TAVARES, Maria das Graças Medeiros et al. A relação expansão-avaliação da educação superior no período pós-LDB/ 1996. Revista Eletrônica de Educação, São Carlos, v. 8, n. 1, p. 92-105, 2014. Disponível em:

http://www.reveduc.ufscar.br/index.php/reveduc/article/view/1014. Acesso em: 14 out. 2017.

TUMOLO, Ligia Maria Soufen. O ENADE como processo de autoavaliação dos cursos de graduação e da Instituição. Cadernos Acadêmicos. Tubarão, SC, v. 2, n. 2, p. 1-14, 2010.

WITTMANN, Lauro Carlos; GRACINDO, Regina Vinhaes (coords.). O estado da arte em política e gestão da educação no Brasil, 1991 a 1997. Brasília: ANPAE; Campinas: Editores Associados, 2001.

ZAINKO, Maria Amélia Sabbag. Gestão da instituição de ensino e ação docente. Curitiba: Ibpex, 2008. 